\title{
Glycemic Status and Lipid Profiles Changes among the Incidentally Diagnosed Fatty Liver Patients
}

\author{
Md. Atiqul Islam¹, Ashraf Uddin Khan², Md. Abdullah Yusuf ${ }^{3}$, Shahana Nasrin ${ }^{4}$, \\ Mohammadunnabi ${ }^{5}$, AHM Rowshon ${ }^{6}$ \\ ${ }^{1}$ Junior Consultant, Department of Medicine, Shaheed Suhrawardy Medical College Hospital, Dhaka, \\ Bangladesh; ${ }^{2}$ Assistant Professor, Department of Radiology and Imaging, Shaheed Suhrawardy Medical \\ College Hospital, Dhaka, Bangladesh; ${ }^{3}$ Assistant Professor, Department of Microbiology, National \\ Institute of Neurosciences \& Hospital, Dhaka, Bangladesh; ${ }^{4}$ Medical Officer, Department of \\ Paediatrics, Shaheed Suhrawardy Medical College Hospital, Dhaka, Bangladesh; ${ }^{5}$ Assistant \\ Professor, Department of Medicine, Abdul Malek Ukil Medical College, Noakhali, \\ Bangladesh; ${ }^{6}$ Professor, Department of Gastroenterology, Shaheed Suhrawardy Medical \\ College Hospital, Dhaka, Bangladesh
}

[Received: January 2015; Revised: March 2015; Accepted: June 2015; Published: January 2016]

\begin{abstract}
Background: Fatty liver disease is common condition. Objective: The purpose of the present study was to see the glycemic status and lipid profiles changes among the incidentally diagnosed fatty liver patients. Methodology: This was an observational descriptive study conducted in the Department of Gastroenterology at Shaheed Suhrawardy Medical College \& Hospital, Dhaka, Bangladesh from the duration of January 2010 to July 2010 for a period of six (6) months. Seventy patients attending indoor or outdoor of Shaheed Suhrawardy Medical College \& Hospital Dhaka, diagnosed ultrasonographically as fatty liver who were met the inclusion and exclusion criteria were recruited. Those subjects who were presented at the outdoor and/or indoor in the hospital for different health problems and were diagnosed as fatty liver on the basis of USG findings were included for this study. Patients of fatty liver diagnosed incidentally by ultrasound, performed for other purposes were planned for study. Blood samples were taken for analysis of risk factors after completing the physical examinations. Result: A total number of 70 patients were recruited for this study. Among the study population, 48 (68.57\%) were between 20-50 years of age, 6 $(8.57 \%)$ were less than 20 years and $16(22.85 \%)$ were more than 50 years. Regarding Glycemic status, $15(21.42 \%)$ cases were Diabetic, $25(35.71 \%)$ cases had impaired glucose tolerance and 30(42.85\%) cases had normal blood sugar. Regarding dyslipidaemia, 51(72.85\%) cases had high triglyceride level $(>150$ $\mathrm{mg} / \mathrm{dl}) ; 42(60 \%)$ cases had hypercholesterimea (>200 mg/dl); decreased HDL (<40 mg/dl) in $37(52.85 \%)$ cases and increased LDL (>150 mg/dl) in $21(44.28 \%)$ cases. Conclusion: In conclusion the abnormal gycemic status and dyslipidemia is present in the incidentally diagnosed fatty liver patients. [Journal of National Institute of Neurosciences Bangladesh, 2016; 2(1): 26-29]
\end{abstract}

Keywords: Glycemic status; lipid profiles; fatty liver; incidentally diagnosed

Correspondence: Dr. Md. Atiqul Islam, Junior Consultant, Department of Medicine, Shaheed Suhrawardy Medical College Hospital, Dhaka, Bangladesh; Email: mdatiqssmc@gmail.com; Cell no.: +8801712514245

Conflict of interest: There is no conflict of interest to any of the authors of this article.

Funding agency: This research work was performed by own cost. There was funding agency had given the support.

Contribution to authors: MAI, AHMR \& SN have contributed form protocol preparation, data collection, analysis and manuscript preparation. MAY has manuscript revision.

How to cite this article: Islam MA, Khan AU, Yusuf MA, Nasrin S, Mohammadunnabi, Rowshon AHM. Glycemic Status and Lipid Profiles Changes among the Incidentally Diagnosed Fatty Liver Patients. J Natl Inst Neurosci Bangladesh, 2016;2(1): 26-29

Copyright: C2016 Islam et al. Published by Journal of National Institute of Neurosciences Bangladesh. This article is published under the Creative Commons CC BY-NC License (https://creativecommons.org/licenses/by-nc/4.0/). This license permits use, distribution and reproduction in any medium, provided the original work is properly cited, and is not used for commercial purposes.

\section{Introduction}

Fatty liver means the accumulation of excess fat $>5-10 \%$ of the weight of the liver specifically in the liver cells ${ }^{1-2}$. It is also called steatosis. A verity of terms have been used to describe this entity, including fatty liver hepatitis, non-alcoholic laennec's disease, diabetic hepatitis, alcohol like liver disease. Non-alcoholic fatty liver disease (NAFLD), the preferred term $\&$ it refers a 
wide spectrum of liver damage ranging from simple steatosis to steatohepatitits, advance fibrosis \& cirrhosis ${ }^{3}$.

It is now clearly decided that NAFLD is strongly associated with metabolic syndrome. Insulin resistance is the fundamental pathophysiology. Obesity $\&$ diabetes are two major risk factors ${ }^{4}$. Hypestriglyceridaemia \& hypertension are frequently associated with NAFLD. For diagnosis of NAFLD requires the exclusion of alcohol abuse as the cause of liver disease. The precise diagnosis of NAFLD and the distinction between hepatic steatosis and steatohepatitits requires a liver biopsys.

For invasive nature of liver biopsy and the lack of effective treatment, patient and physician are off often reluctant to pursue diagnosis with vigor. To know the etiologies of faulty changes of liver will help in taking appropriate measure to treat those conditions in order to prevent complications in the form of fatty liver ${ }^{6}$. This may help in reduction of liver related morbidity \& mortality. No study is so far done in Bangladesh so far in this regards. Therefore, this present study was undertaken to see the glycemic status and lipid profiles changes among the incidentally diagnosed fatty liver patients.

\section{Methodology}

This was an observational descriptive study which was conducted in the Departemtn of Gastroenterology at Shaheed Suhrawardy Medical College \& Hospital, Dhaka, Bangladesh from the duration of January 2010 to July 2010 for a period of six (6) months. Seventy patient attending indoor or outdoor of Shaheed Suhrawardy Medical College \& Hospital Dhaka, diagnosed ultrasonographically as fatty liver who were met the following inclusion and exclusion criteria were recruited. Those subjects who presented at the outdoor and or indoor in the hospital for different health problems and diagnosed as fatty liver on the basis of USG findings. Liver biopsy could be the best to diagnose fatty liver as it is the gold standard. But, as we are taking otherwise normal subjects for study, they may not agree to have these invasive procedures done on them. Subject who took Alcohol on the regular basis, subject who were unwilling to be include in this study or did not give consent, extreme of age and presence of co-morbid condition, such as stroke, unconscious, heart failure were excluded from this study. Patients of fatty liver diagnosed incidentally by ultrasound, performed for other purposes were planned for study. Seventy patients who meet the inclusion and exclusion criteria and gave the informed written consent to be included in the study were finally selected. Data were collected by using a semi structured questionnaire by the researcher with face to face interview. Blood samples were taken for analysis of risk factors after completing the physical examinations. Results of physical examination and blood sample were entered in to a computer generated analysis program. Data were entered in a previously prepared computer program. The numerical data obtained from the study were analyzed by using computer based Statistical Programs for Social Science (SPSS) version 16. Data were expressed in number and percentage, and show in tabulated forms, pie charts and bar diagrams. The study was conducted with prior ethical clearance of Ethical Committee of Bangladesh Medical Research Council. Before data collection, informed written consent was taken from the respondent. Moreover confidentiality of collected data was maintained with highest priority. De-identified data were be preceded for analysis.

\section{Results}

A total number of 70 patients were recruited for this study. Among the study population, $48(68.57 \%)$ were between $20-50$ years of age, $6(8.57 \%)$ were less than 20 years and $16(22.85 \%)$ were more than 50 years (Figure I).

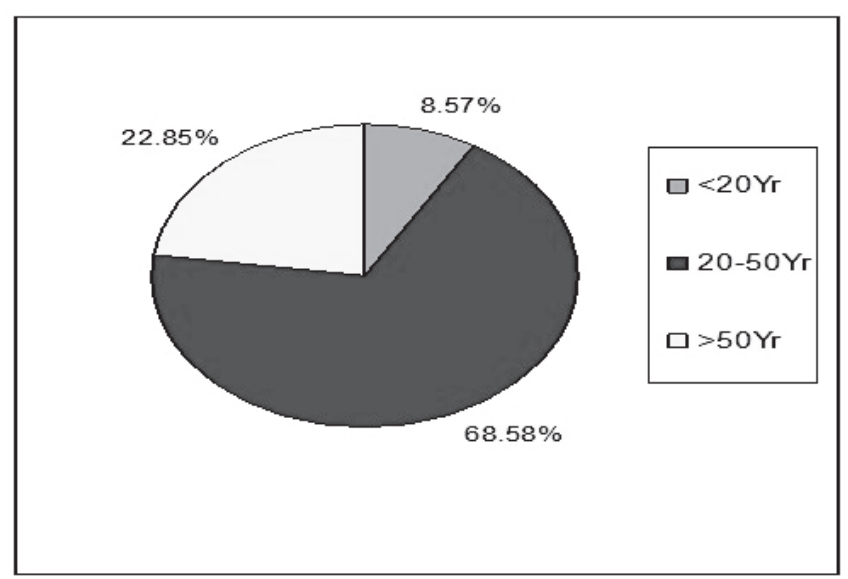

Figure 1: Distribution of study population according to age

Regarding Glycemic status, 15(21.42\%) cases were Diabetic, 25(35.71\%) cases had impaired glucose tolerance and 30(42.85\%) cases had normal blood sugar (Figure II). 


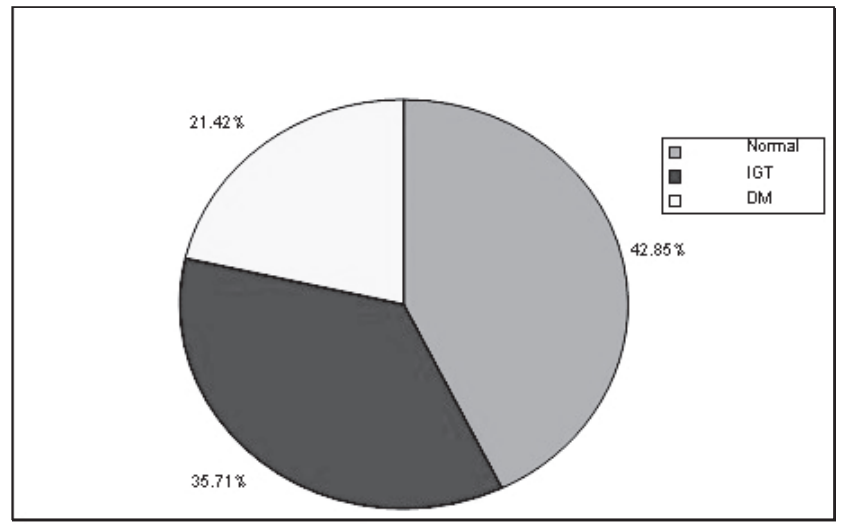

Figure II: Glycemic status of study population

Regarding dyslipidaemia, 51(72.85\%) cases had high Triglyceride level (>150 mg/dl); 42(60\%) cases had hypercholesterimea $(>200 \mathrm{mg} / \mathrm{dl})$; decreased HDL $(<40 \mathrm{mg} / \mathrm{dl})$ in $37(52.85 \%)$ cases and increased LDL $(>150 \mathrm{mg} / \mathrm{dl})$ in $21(44.28 \%)$ cases (Table 1).

Table 1: Lipid profile status among study population

\begin{tabular}{lcc}
\hline Lipid profile & Frequency & Percentage \\
\hline Cholesterol $(>200 \mathrm{mg} / \mathrm{dl})$ & 42 & 60.0 \\
Triglyceride $(>150 \mathrm{mg} / \mathrm{dl})$ & 51 & 72.85 \\
HDL $(<40 \mathrm{mg} / \mathrm{dl})$ & 37 & 52.85 \\
LDL $(>150 \mathrm{mg} / \mathrm{dl})$ & 21 & 44.28 \\
\hline
\end{tabular}

\section{Discussion}

Non-alcoholic fatty liver disease is not an uncommon condition which represents a wide spectrum of disorders. The hallmark of which is hepatic steatosis. NAFLD was thought to be a benign condition but is now increasingly recognized as a major cause of liver related morbidity and mortality. The disease encompasses not only simple steatosis but also includes nonalcoholic steatohepatitis, advanced fibrosis and cirrhosis of liver. Total 70 cases were selected who incidentally diagnosed as fatty liver disease by USG, done for other purpose(s) and who are not unwilling to be a subject of the study.

Most of the cases are in the age group of 20 to 50 years $(68.57 \%)$ followed by less than 20 years which was $8.57 \%$ cases. Schwimmer et $\mathrm{al}^{7}$ have shown that the prevalence of fatty liver between the age of 2 to 19 years is $9.6 \%$ which is very close to this present study result. Another study by $\mathrm{Li}$ et $\mathrm{al}^{8}$ have shown the prevalence of fatty liver increased with age in female and males of less than 50 years which also corresponds to the present study.

David et $\mathrm{al}^{9}$ showed that a high glycaemic index diet to cause fatty liver and low glycaemic index diets to prevent fatty liver in human. An important risk factor for NAFLD is Insulin resistance. In this study it has been found that $21.42 \%$ of study population is of type 2 diabetes and $35.71 \%$ having impaired glucose tolerance. Haiso et $\mathrm{al}^{10}$ showed that $7.6 \%$ of cases was diabetic and $39.5 \%$ of cases was IFG. The result of both studies is almost similar.

Dyslipidemia has a significant impact on NAFLD. In this study $72.85 \%$ patient had hypertriglyceridemia $(>150 \mathrm{mg} / \mathrm{dl})$, decreased high density lipoprotein $(<40 \mathrm{mg} / \mathrm{dl})$ in $52.85 \%$ patient, hypercholesterolemia $(>200 \mathrm{mg} / \mathrm{dl})$ in $60 \%$ patient. Parekh et $\mathrm{al}^{11}$ showed that the prevalence of hyperlipidemia associated with NAFLD varies from 20.0 to $92.0 \%$ where hypertriglyceridemia rather than hypercholesterolemia appears to be the major risk factors in this association. There is several limitation of the study. This is a small scale study, done on only 70 patients on the basis of ultrasonographic findings. Ultrasonography can't distinguish simple steatosis from cirrhosis, as fatty filtration of liver produces a diffuse increase in echogenicity as compared with the kidney and cirrhosis has a similar appearance on USG. Ultrasonography has a sensitivity of $89 \%$ and a specificity of $93.0 \%$ in detecting steatosis and a sentivity and specificity of $77.0 \%$ and $89.0 \%$ respectively in detecting increased fibrosis. Liver biopsy is the gold standard for detecting fibrosis and cirrhosis. In our study we cannot perform liver biopsy for financial constraint and patients disagreement. Other important investigations such as HBV DNA, $\mathrm{HBeAg}$, Prothrombin time which are also an important indicators of liver injury such as fibrosis and cirrhosis, can't be done for financial constraint.

\section{Conclusion}

In conclusion the abnormal gycemic status and dyslipidemia is present in the incidentally diagnosed fatty liver patients. A large study by including huge number of population from all sectors the community should be done.

\section{References}

1. Adams LA, Lymp JF, St Sauver J, Sanderson. So, Linder KD, Feldstein A. Angulo P. The natural history of non alcoholic fatty liver disease: A population based cohort study. Gastroenterology 2000;129(1): 113-21

2. Crabb DW, Galli A, Fischer M, You M. Molecular mechanism of Alcoholic Fatty Liver: role of peroxisome proliferator-activated receptor alpha. Alcohol 2004;34(1):35-8

3. Poul A. Non alcoholic fatty liver disease. N Eng J Med 2002: 346; 1221-31

4. Clark, Bancati FL, Diehl AM. The prevalence and etiology of 
elevated aminotransferase levels in United States. AM J Gastroenterol 2003;98:960-67

5. Ramesh S, Sanyal AJ. Evaluation and management of non alcoholic steatohepatitis. J Hepatol 2005;42:S2-S12

6. Ludwing J, Viggiano TR, Megel DB. Non alcoholic steatohepatitis Mayo clinic experiences with a hitherto unnamed disease. Mayo Clin Prac 1980;55:434-38

7. Schwimmer JB, Deutsch R, Kahen T, Lavine JE, Stanley C, Behling C. Prevalence of fatty liver in children and adolescents. Pediatrics 2006;118(4):1388-93

8. Li H,Wang YJ, Tan K, Zeng L, Liu L, Liu FJ, Zhou TY, Chen $\mathrm{EQ}$, Tang H. Prevalence and risk factors of fatty liver disease in
Chengdu, Southwest China. Hepatobiliary Pancreat Dis Int 2009;8(4):377-82

9. Ludwig D. Quick-burning carbs may cause fatty liver. Viewed on June 2013; [Web Address: www.childrenhospital.org/newsroom/Site1339/mainpageS1339P1sublevel1341.html]

10. Hsiao PJ, Kuo KK, Shin SJ, Yang YH, Lin WY, Yang JF, Chiu CC, Chuang WL, Tsai TR, Yu ML. Significant correlations between severe fatty liver and risk factors for metabolic syndrome. J Gastro Hepatol 2007;22(12):2118-23

11. Parekh S, Anania FA. Abnormal lipid and glucose metabolism in obesity: implications for nonalcoholic fatty liver disease. Gastroenterology. 2007;132(6):2191-207 